ORIGINAL ARTICLE

\title{
Application of Higher Diploma Program training skills in classroom instruction: The case of Education Faculty, Jimma University (Ethiopia)
}

\author{
Adula Bekele Hunde*
}

\begin{abstract}
This article examines the application Higher Diploma training skills in classroom instruction as well as pinning to the possible bottlenecks that hamper the successful application of the training skills. To this end, graduates of the first two batches, heads of the ten departments operating under the Faculty of Education and dean of the faculty were participated in the study. Multiple instruments with multiple sources were used in data collection in the following order: classroom observation, interview with the corresponding graduate, interview with the heads and finally interviewing Faculty Dean. The study implied that graduates were not applying Higher Diploma Training skills to the expected level. Factors for the failure of implementing Higher Diploma Program training skills at a classroom level attributed not only to the physical constraints such as large class size, lack of learning materials at hand, and mismatch between course content and time allotted but also to the absence of interest from instructors and students side and absence of well organized follow-up support that enforces or reinforces instructors to use the training skills. The study wrapped up with some plausible recommendations that allievate or minimizes the effect of barriers.
\end{abstract}

\section{INTRODUCTION}

\subsection{Background of the study}

An extensive study was conducted by Ministry of Education in 2002 covering the overall education system of Ethiopia and teacher's education system in particular
(Teacher Education System Overhaul [TESO], 2003). The study revealed that Ethiopian Teachers educators failed to form spearhead in educational development endeavor. The teaching learning process they were employing so far was teacher

Lecturer, department of Pedagogy, Faculty of Education, Jimma University Academic Development and Resource Center Expert

E-mail: adulabekele@yahoo.com 
dominated talk and blackboard use. The study attributed the major cause of the problem to the fact that teacher educators have received very little or no opportunity to undertake appropriate and necessary staff development that could enable them to perform their key roles in rendering preservice and in-service education in line with a student centred approach. Consequently, TESO was established under the ministry of education, with sub committees in order to tackle the underlying problems.

Accordingly, the first action taken by TESO was designing curriculum material in modular approach following the educational policy of Ethiopia that aimed at developing the culture of active learning and problem-solving approach of instruction (Federal Democratic Republic of Ethiopia [FDRE], 2004). In order to implement the material, Higher Diploma Program [HDP] was designed and is being provided to teacher educators. Of course, the objective of HDP is not merely to professionalize teacher educators in line with promoting a student-centred approach but also emphasize the overall professional growth of teachers. It is on-the-job training for one academic year targeting at ensuring the competence in learning and teaching methods, assessment methods as well as key elements of the roles required of teachers' educators: reflection, collaborative work, planning and coping to change. To this end, the training of HDP comprises the following major teams: reflective educator, time management, active learning methods, continuous assessment, and school placement and action research. Thus, the successful completion of the one-year Higher Diploma Program Training will be the prerequisite for receiving a teaching license without which no one can join or stay in the profession in future (TESO, 2003).
The program is a government initiative and the control is highly centralized. Hence, the same practice is taking place in all TEIs and University's Faculty of Education in Ethiopia. The program was launched in 2003/04 and by now (as of August 2008), four batches have graduated. Nevertheless, this article focused on analyzing the extent to which graduates of the first two bathes are applying the training skills into their classroom instruction.

\subsection{Statements of the problem}

The need for a professional development program for the teacher educators in Ethiopia has been reflected in Section 1.1 of this article. In response to this need, government has initiated HDP, a groundbreaking in the history of in-service training in the country's education system. It is one year on-job training that provides an opportunity for instructors to try immediately the training skills in their classroom teaching and reflect upon it. The presence of classroom observation by the program leaders and observation from peers during classroom teaching increases the novelty and effectiveness of the program. This process lets the practitioners to receive constructive feedback as to what went good and areas that need improvement in their approach. Apart from this, instructors plan their lesson based on the training they are receiving, conduct a session, and evaluate the lesson and again plan for improvement. The leaders will evaluate progress of each instructor by referring to the individual teacher educators' portfolios.

Literature on staff development practice indicates that the success of a given professional development training measured by the degree of the transfer of the training skills into classroom instruction (Guskey, 2000). Conducting outcome assessment at the classroom level 
can do this. According to Guskey, outcome assessment enabled the concerned body to identify the extent to which the training skills are realized at the classroom level, point to the possible bottlenecks for the successful application and taking progressive action based on the feedback obtained. This will enhance the sustainability of the program. However, outcome assessment of HDP at Jimma University in the Faculty of Education with the intention of articulating the extent to which the graduates are using the training skills at the actual classroom level has not yet studied. Consequently, this study initiated to cover the gap mentioned but focusing only on skills that can be observed and assessed during classroom instruction (such as application of active learning, continuous assessment and time management). In addition, the study addressed the possible limitations that hindered the application of the training skills to the optimal level. Thus, the study guided by the following research questions:

- To what extent HDP graduates are using the training skills (active learning, continuous assessment and time management) in their classroom teaching?

- What are the possible bottlenecks that hinder instructors from using HDP training skills in their classroom instruction?

\subsection{Objective of the study}

\subsubsection{General objective}

This study intended to assess the application of HDP training on the current classroom instruction of the graduates and pinning to bottlenecks that inhibit graduates from using skills to the optimal level.

\subsubsection{Specific objectives:}

- Determine the extent to which HDP graduates are applying HDP training skills (active learning, continuous assessment and time management) in their classroom instruction

- Identify the barriers for implementing HDP training skills in class room instruction

- Recommend strategies that could escalate the application of HDP training skills into classroom teaching.

\subsection{Significance of the study}

The study tried to assess the application of HDP training skills at actual setting and this revealed the real picture of the current status of the application of the program at classroom instruction. Based on that possible recommendation that would maximize the impact of the training have provided. Therefore, this would help the concerned body at different level (Ministry of Education, Teacher Education Institutions, Education faculty as well as the coordinator of HDP) to revisit their procedure, which result in effectiveness and sustainability of the program. Moreover, the study can help as a springboard for those who want to conduct further investigation on similar area.

\section{METHODOLOGY}

\subsection{Research design}

Cross sectional study employed to assess the outcome of HDP training on the classroom instruction of the graduates.

\subsection{Study site}

This study was conducted in education faculty, University of Jimma (Ethiopia). The Education Faculty was selected for this study since HDP has been introduced only in this faculty. HDP training is rendering to 
the eleven departments operating under the faculty. Hence, this study included all departments except department of Physical education for mode of delivery utilized by that department was not conducive for classroom observation. Besides, nobody was there for interview as graduating staffs from the department have already left for further study. Although department of Psychology and Civics Education were involved in the training till recently, they were not included in the study since they have established as applied science faculty merging with other new departments.

\subsection{Population}

The population of this study consisted of all graduates of HDP working in the Faculty of Education. This group of instructors was appropriate for this study as it would help the researcher to get reliable and first hand information on the application of HDP training skills and challenges they have faced in applying the skills in classroom teaching. All department heads, and Dean of the faculty were involved in the study. They are also valuable source as they are responsible for all developments undertaking in their respective department and the faculty as a whole. Fullan (1991) put the contributions of institution's head for realization of reformation stating as organizations change become effective when administrators of the organization play active role in helping to lead the improvement. Lists of the HDP gradates is presented in table 1 .

Table 1: Lists of Higher Diploma graduates by department in the faculty of Education Jimma University.

\section{List of departments}

\begin{tabular}{lllllllllllllll}
\hline & \\
&
\end{tabular}

Source: HDP office, Faculty of Education in Jimma University

Note: All participants were males as no female instructors were employed in the faculty before 2004/05

* HPE refers to Health and Physical Education

\subsection{Sampling}

It can be impossible for the researcher to interview or conduct classroom observation with all graduates of the HDP. At the same time, the population size (see Table 1) for each department and the nature of the study (i.e. forcing somebody for interview or classroom observation is difficult if not impossible) were not convenient for applying random sampling. As a result, one voluntary graduate was selected for classroom observation and subsequent interview from all departments except one (See Section 2.5). 


\subsection{Instruments}

In this study, a variety of instruments were used to collect information about the HDP graduates use of the training skills in classroom instruction and identifying factors that might inhibit the successful transfer of the skill in actual teaching.

\section{Classroom observation}

Classroom observation was conducted in order to collect first hand information regarding the current use of HDP training skills in classroom instruction. Accordingly, nine lessons (one from each department) were observed by means of an observation checklist. The observation checklist were adopted from Thijs (1999) and Ottenvanger (2001) following the style of HDP. An expert appraisal was used to ensure whether the adopted checklists could fit to the HDP or not. Generally, the observation checklist focuses on HDP graduates (instructors) use of HDP training skills: learner centred approach with reference to active learning, continuous assessment and time management in their classroom instruction. To this effect the observation checklist with three parts has prepared: Introduction, Body of the lesson and Conclusion.

\section{Interview}

The main instrument used in this study was interview. It helped the researcher to collect information from different sources. In the first instance, interview used to collect information from graduates of HDP after the observation as to their use of a HDP training skills and the challenging factors for the application of the training skills.

\subsection{Procedures}

First, the researcher visited the faculty and met V/dean of the faculty and discussed the purpose of the research activity showing the support letter, which was later distributed to all departments through office of V/Dean. Then, the researcher approached to select one HDP graduates from each department. The selection took place in such away that the researcher visited the department in the morning and asked the target instructor, clarifying the objective of the research, if he/she was willing to be observed during his/her classroom instruction and then interviewed. Then, the classroom observation, with the help of observation checklist, occurred on the same day in order to observe the "natural circumstances". The observation focuses on areas of HDP training skills that can be applied at a classroom level (such as use of active learning, continuous assessment and time management). Data collection during classroom observation took place in such away that the researcher took notes thereby tick as yes, no or not applied (N/A) immediately after the session.

Then interview was held with the respective instructor, then the respective department head and finally with the dean to investigate further about application of HDP training skills and factors they think could hindered the application to reach its optimal level. Interview used the semistructured interview guide that could let the interview to express his/her feeling freely, let the researcher use ideas from the observation (in contrary to the well structured one) and at the same time more convenient for analysis purpose than the unstructured interview (see Wragg, 2002; Silverman, 1993). Wragg (2002) portrays the significant influence of interview place and time for the validity and reliability of information provided by the interview. For that matter, interview places for study were arranged where privacy was maintained based on agreement with the interviewee. Similarly, time for the interview was set in such away that the interviewee would not get tired. Wrang, also plea for not to make 
interview for very brief time that lead to shallow of information, also not to make it too long for fear of fatigue. $\mathrm{He}$ recommends optimal time range for interview as forty-five minutes to an hour. The number of questions and scope of each interview guide questions for this study set taking into consideration the aforementioned time gap. In order to determine the time limit for interview as well as validity of the interview guide questions, Wragg comments making use of pilot study in two ways: Soliciting comment from the experienced person and trying one or two pilot interviews. This study used only the former mentioned technique for two reasons: time constraint to conduct pilot interview for all sources and limited number of sources (see Table 1).

\subsection{Quality aspect of the data}

Yin (1994) suggests that construct validity of a case study can be maintained by using multiple sources of information and by establishing chain of evidences. This study is abided by these rules. Accordingly, the researcher used multiple sources and multiple instruments. Besides, the researcher tried to link the items (classroom hecklist and interview guide) to the two research questions. Besides, the attempt done to observe "natural environment" and the sequence of data collection process (observation-interview with the observed teacher-interview with the heads and dean) guaranteed the quality it wants.

\subsection{Data analysis}

This research used both qualitative and quantitative aspect of data analysis. The data obtained from classroom checklist was quantitatively analyzed. The data collected with the help of interview from each interviewee would be transcribed, and coded with reference to the research questions. The data collected from different (group) sources analyzed independently following the research questions. Finally, summary of data from all sources and instruments discussed all together. Then conclusion and recommendation were drawn.

\section{RESULTS}

This section presents the findings of the study. It begins from portraying the general overview of respondents to describing findings from classroom observation and interviews.

As shown in Table 2, all respondents were male as far as no female instructors have undergone HDP during the first two batches. With regard to participants' educational background, all have their second degree except two and all of them have undergone teacher education system in either of their degrees despite the fact that teachers in Ethiopia who have not yet received pedagogical training can join teaching profession up to the introduction of HDP. Mean year for teaching experience for participants was 12, with a range of 3 to 20. The same table also depicted that the average teaching load for instructors was 11 hours per week excluding other related activities such as advising and supervising CBTP and the average number of courses taught by the respondents was 2 , with a range of 1 to 3 . 


\subsection{General overview of the respondents}

Table 2: Demographic characteristics of the participants (instructors)

\begin{tabular}{lllllll}
\hline & & & & & & \\
\hline
\end{tabular}

Note: The researcher could not manage to observe any of HDP graduates from Mathematics department as some of them were not around during data collection while others reported that they have already completed classes. $\mathrm{TS}=$ teaching stream

Similarly, background information about department heads is presented in Table 3 .

Table 3: An overview of department heads' characteristics

\begin{tabular}{|c|c|c|c|c|}
\hline $\begin{array}{l}\text { Departme } \\
\text { nts }\end{array}$ & Gender & $\begin{array}{l}\text { Educational } \\
\text { level }\end{array}$ & Age & $\begin{array}{l}\text { Experience as a department head } \\
\text { (in year) }\end{array}$ \\
\hline
\end{tabular}

\begin{tabular}{lllll}
\hline A/ Oromo & M & MA & 32 & 3 \\
\hline Amharic & M & MA & 33 & 2 \\
\hline English & M & MA & 32 & $9 / 12$ \\
\hline $\begin{array}{l}\text { Mathemati } \\
\text { cs }\end{array}$ & M & MSc & 35 & 1 \\
\hline Geography & M & MA & 36 & 2 \\
\hline History & M & MA & 30 & $4 / 12$ \\
\hline Biology & M & MSc & 34 & 2 \\
\hline Chemistry & M & MSc & 30 & $4 / 12$ \\
\hline Physics & M & MSc & 26 & $4 / 12$ \\
\hline Pedagogy & M & MA & 30 & 3 \\
\hline Mean & - & & 32 & $15 / 12$ \\
\hline S.D & - & - & 0.9 & .78 \\
\hline
\end{tabular}


As shown in Table 3, all department heads have their second degree and they were found in early adulthood (average age 32 years of age). Their experience as a department head varied from 4 months to 3 years with mean of almost 1.5. Under the normal condition, position of department head is rotating within 2 years although literatures recommend a minimum length of term of office three years (Higher Education System Overhaul [HESO] (2004).
Believing that teaching load of instructors, number of courses taught and the number of teaching staffs on duty significantly influences the application of HDP training skills (active learning methods, continuous assessment and time management) by competing for time and energy, heads were asked to report situation of their departments. Their responses are presented in table 4.

Table 4. Average teaching load, number of subjects taught by each teacher and number of teaching staffs by respective departments

\begin{tabular}{llll}
\hline Department & $\begin{array}{l}\text { Teachin } \\
\text { g load }\end{array}$ & $\begin{array}{l}\text { No of subjects taught by } \\
\text { each instructor }\end{array}$ & $\begin{array}{l}\text { Teaching staff } \\
\text { (On duty) }\end{array}$ \\
\hline A/ Oromo & 9 & 2 & 6 \\
\hline Amharic & 10 & 2 & 7 \\
\hline English & 18 & 1 & 27 \\
\hline Mathematics & 12 & 2 & 13 \\
\hline Geography & 8 & 2 & 7 \\
\hline History & 12 & 2 & 8 \\
\hline Biology & 10 & 2 & 9 \\
\hline Chemistry & 9 & 3 & 12 \\
\hline Physics & 12 & 2 & 9 \\
\hline pedagogy & 12 & 1 & 11 \\
\hline Mean & 11 & 2 & 11 \\
\hline S.D & .88 & .15 & 1.9 \\
\hline
\end{tabular}

Thus, as shown by Table 4, the average teaching load of departments ranges from 8 to 18 , with mean value of 11 . The table also depicted that instructors in the majority of the department occupied 2 courses per semester. The number of teaching staff on duty varied from 6 (A/ Oromo department) to 27 (English department) while the mean was 11 . English department is with high number of teaching staff (27) and teaching load at the same time. However, on average, they are rendering only one course like Pedagogy department. This happened since English department is offering common courses for all departments operating in the University. Pedagogy department shared similar characteristics by offering courses for all departments within the Education Faculty. On contrary side, A/ Oromo, Geography and Amharic departments are running with relatively few staffs $(6,8, \& 10$, respectively) but with minimum teaching load $(9,8, \& 10$, respectively).

\subsection{Findings of classroom observation}

Classroom observation was used to assess how far HDP training skills were used in real classroom practice. This provided good insights into the real life application of a 
student-centred approach by graduates of HDP. The observation was conducted with the help of checklists addressing the introduction, body of the lesson and conclusion part. Accordingly, one instructor from each department except Mathematics was observed. Summaries of the observed lessons are provided in Table $5 \mathrm{a}$ and $\mathrm{b}$.

Table 5a. Summary of findings from observation checklist

List of instructors

\begin{tabular}{lcccccccccc} 
& $* \mathrm{I} 1$ & $\mathrm{I} 2$ & $\mathrm{I} 3$ & $\mathrm{I} 4$ & $\mathrm{I} 5$ & $\mathrm{I} 6$ & $\mathrm{I} 7$ & $\mathrm{I} 8$ & $\mathrm{I} 9$ & $\mathbf{X}$ \\
Class size** & 65 & 65 & 80 & 40 & 70 & 40 & 65 & 40 & 40 & $\mathbf{5 6}$ \\
& & & & & & & & & & \\
\hline Introduction: Basic teaching skill & 60 & 20 & 20 & 20 & 40 & 40 & 20 & 20 & 20 & $\mathbf{2 9}$
\end{tabular}

\begin{tabular}{|c|c|c|c|c|c|c|c|c|c|c|}
\hline $\begin{array}{c}\text { Learner centred } \\
\text { Orientation }\end{array}$ & 67 & 0 & 0 & 100 & 50 & 67 & 100 & 90 & 50 & 58 \\
\hline \multicolumn{11}{|l|}{ Body of the } \\
\hline Lesson: Basic teaching skill & 0 & 0 & 25 & 45 & 25 & 25 & 0 & 50 & 50 & 24 \\
\hline $\begin{array}{c}\text { Learner centred } \\
\text { Orientation }\end{array}$ & 0 & 0 & 9 & 55 & 28 & 36 & 36 & 50 & 100 & 34.5 \\
\hline Conclusion: Basic teaching skill & 0 & 67 & 0 & 0 & 100 & 100 & 67 & 0 & 33 & 41 \\
\hline $\begin{array}{c}\text { Learner centred } \\
\text { Orientation }\end{array}$ & 0 & 25 & 0 & 50 & 100 & 50 & 75 & 50 & 25 & 42 \\
\hline
\end{tabular}

Note: Except for class size the other were referring to the percentage of items that marked as yes. ${ }^{*} \mathrm{I}=$ Instructor

** The figure for class size indicated the approximate number of students on the day of classroom observation, as agreed by researcher and classroom teacher.

As can be seen in table 5a, a student centred approach was hardly implemented by the majority of the participants. They failed to move smoothly through the whole lesson using a student-centred approach. Majority of them made good use of introduction part, except I2 \& I3). However, as they began body of the lesson, which is the most determinant part and for which many items set as teachers are also expected to devote much time, all instructors with exception of I4, I9 \& relatively $\mathrm{I} 8$, tended to fall back to the traditional lecture method. However, majority of respondents who have completed the lesson on time, tried to involve students at least by inviting them to raise unclear issue while concluding the lesson.

In addition to the checklist with detailed items to collect information about classroom practice discussed above, other general items focusing on HDP objective used to get the general impression of the lesson. The items were open ended but later, after collection of data taken place, converted into yes, no and N/A for the sake of simplicity for analysis. And this can be shown in Table 5 b as follow. 
Table $5 b$. General Impression of the lesson $\mathrm{N}=9$

\begin{tabular}{lllr}
\hline Expected outcome & Yes & No & N/A \\
\hline Student teacher talk balance & $2(22 \%)$ & $7(78 \%)$ & $0(0 \%)$ \\
\hline Use of varieties of active learning Methods & $3(33 \%)$ & $6(67 \%)$ & $0(0 \%)$ \\
\hline Use of continuous assessment & $2(22 \%)$ & $7(78 \%)$ & $0(0 \%)$ \\
\hline Time management & $0(0 \%)$ & $0(0 \%)$ & $9(100 \%)$
\end{tabular}

As it can be seen in the Table 5b, only two instructors teaching national and regional language succeeded in conducting lesson maintaining teacher student talk balance. Specially, it was only these two instructors that were shown positively encouraging the participation of female students.

With regard to the use of varieties of active learning methods, instructors who were observed using other active learning methods in addition to or instead of the normal lecture method, gaped lecture, and questions were categorized as yes he/she was using varieties of active learning methods. Accordingly, only three instructors ( as shown in Table 5b) were used other active learning methods such as cross over group ( I9), presentation ( I9 \& I8), individual work ( I4, \& I8) and group discussion ( I4 , I9).

In response to item sought general impression about instructors' use of continuous assessment, specific to use of self evaluation, peer evaluation and group evaluation, only the aforementioned language instructors used it. Although not able to use the aforementioned techniques of continuous assessment almost all instructors were checking the understanding of their students through questioning, roaming around and observing what they were doing. However, even going within the class was difficult for some instructors as there was no pass. For instance, I2 gave activity for his student to show him by drawing the picture. Finally, since no way for students to go to the blackboard and for the teacher to approach the student, the student showed the picture by sign remained seating on his bench.

One of the objectives of HDP is equipping instructors with skill of managing time or adapting to changes. As a result, instructors are recommended to use lesson plan for their teaching. However, non of participants observed using a lesson plan. They informed the researcher that they used lesson plan only during classroom observation by HDP leader or peer during HDPT. As a result, it was difficult for researcher to generalize about time management of the observed instructors.

\subsection{Instructors response on interview questions}

After classroom observation, instructors were asked to describe the then lesson inline with a student-centred approach from their own point of view. Accordingly, the interview responses schemed as a studentcentred approach was implemented, implemented but not accurately and not implemented. This is provided in table 6 below. 
Table 6. Application of a student centred approach by HDP graduates

$\mathrm{N}=9$

\begin{tabular}{lc}
\hline Implemented & $2 \mathrm{x}$ \\
\hline Implemented but not accurately & $4 \mathrm{x}$ \\
\hline Not Implemented & $3 \mathrm{x}$ \\
\hline
\end{tabular}

As shown in Table 6, although the observation result showed that relatively three instructors were applied a studentcentred approach, it was only two of them that considered their then lesson as participatory. These two instructors were teaching national (I8) as well as regional language (I9). Whereas, relatively high number of instructors $(4 \mathrm{x})$ and $(3 \mathrm{x})$ considered their then lesson as a student centred approach was not accurately applied and not applied at all, respectively.

However, from those who claimed that their then lesson was a student centred, one instructor (I8) revealed that he usually uses traditional lecture method unlike the then lesson. He expressed his idea as follow:

"As a matter of chance my today's lesson is activity based. It is doing exercises. As a result, I used participatory approach. My course is more of theory based that obtained from different books. However, my students are not matured to read and understand such books. Therefore, it usually requires me to translate the idea of such books to the language of instruction [one of Ethiopian languages]. As a result, most of the time I utilizes traditional lecture method"
I9 mentioned that both at the day of classroom observation by researcher as well as at other time he is continuously using active learning methods. For instance, he stated the then lesson as follow:

"...as to my observation I believe that I utilized student centred approach effectively because they [students] were contributing to the classroom discussion more than I did. As you observed them they were first dealing with issue individually, then discussed in pair, then in groups and finally report their finding through their representative where heated discussion occurred"

Moreover, In order to cross check how far the HDP graduates are using active learning methods learnt during HDP training, they were requested to recall at least five of them among the many lists they have/learnt or practice during HDP training. The rationale for this was that if they are really using these methods, they could recall at least their names. Their responses were presented in Table 7. 
Table 7. List of active learning methods named with the corresponding instructor's department

\begin{tabular}{|c|c|c|c|c|c|c|c|c|c|c|}
\hline & & & & & \multicolumn{6}{|c|}{ Respondent's department $(n=9)$} \\
\hline $\begin{array}{l}\text { Name } \\
\text { active } \\
\text { learning } \\
\text { method }\end{array}$ & 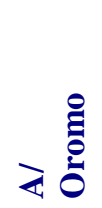 & 恣 & 氮 & 항 & $\sum_{\substack{n\\
}}^{n}$ & 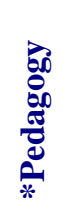 & 䍖 & 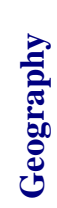 & 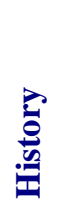 & 预 \\
\hline $\begin{array}{l}\text { Group } \\
\text { discussion }\end{array}$ & $\sqrt{ }$ & $\sqrt{ }$ & $\sqrt{ }$ & & $\sqrt{ }$ & & & $\sqrt{ }$ & & 5 \\
\hline $\begin{array}{l}\text { Individual } \\
\text { work }\end{array}$ & & $\sqrt{ }$ & $\sqrt{1}$ & & $\sqrt{ }$ & & $\sqrt{ }$ & & & 4 \\
\hline Questioning & $\sqrt{ }$ & & & $\sqrt{ }$ & & & $\sqrt{ }$ & $\sqrt{ }$ & $\sqrt{ }$ & 5 \\
\hline presentation & & $\sqrt{ }$ & & & & & $\sqrt{ }$ & $\sqrt{ }$ & & 3 \\
\hline demonstration & & $\sqrt{ }$ & & $\sqrt{ }$ & & & & & $\sqrt{ }$ & 3 \\
\hline Buzz Group & & & & & & & $\sqrt{ }$ & $\sqrt{ }$ & & 2 \\
\hline Gold fish ball & & & $\sqrt{ }$ & & & & & $\sqrt{ }$ & & 2 \\
\hline Gap-lecture & & $\sqrt{ }$ & & & & & & & $\sqrt{ }$ & 2 \\
\hline $\begin{array}{ll}\text { Hot } & \text { seat } \\
\text { system }\end{array}$ & $\sqrt{ }$ & & & $\sqrt{ }$ & & & & & & 2 \\
\hline Pair work & $\sqrt{ }$ & & $\sqrt{ }$ & & & & & & & 2 \\
\hline $\begin{array}{l}\text { Cooperative } \\
\text { learning }\end{array}$ & & & & $\sqrt{ }$ & & & & & & 1 \\
\hline Group work & & & & $\sqrt{ }$ & & & & & & 1 \\
\hline $\begin{array}{l}\text { Peer } \\
\text { evaluation }\end{array}$ & $\sqrt{1}$ & & & & & & & & & 1 \\
\hline total & 5 & 5 & 4 & 5 & 2 & - & 4 & 5 & 3 & \\
\hline
\end{tabular}

Note: $\mathrm{n}$ does not add up to the total as one respondent provided more than one response. 0

* Item addressing the required response was jumped unintentionally for instructor from Pedagogy department.

As shown in table 7, only instructors from four departments named active learning methods up to five. The methods reported with high frequency were group discussion $(5 \mathrm{x})$, questioning $(5 \mathrm{x})$, and individual work (4x). These are the commonly known and used methods. Here, five instructors were named the name of group discussion but only two instructors were observed using this approach. Generally, this shows that they are not accurately exercising with the active learning methods learned during HDP training even though do not abandon them at all.

Instructors who have mentioned that they did not use a student-centred approach at all or partly in their lesson have provided justification for their responses. These are shown in Table 8 by descending order. 
Table 8. Justification for not applying a student-centred approach as provided by instructors

\begin{tabular}{lc} 
Reasons for not using a student centred approach & $\mathrm{N}=7 *$ \\
\hline Large class size & $4 \mathrm{x}$ \\
\hline The need to cover portion & $4 \mathrm{x}$ \\
\hline
\end{tabular}

Lack of learning materials $2 \mathrm{x}$

Lack of interest from the student side $2 \mathrm{x}$

\begin{tabular}{ll}
\hline Nature of the lesson & $2 \mathrm{x}$
\end{tabular}

"To behave as usual " $2 \mathrm{x}$

* $\mathrm{N}$ does not add up to total as one respondent provided more than one response.

As shown in Table 11, the need for covering portion $(4 \mathrm{x})$ and large class size $(4 \mathrm{x})$ were among the frequently indicated barriers for application of a student-centred approach reported by instructors. Lack of learning materials at hand, lack of interest from student side, nature of the lesson and the request from the researcher to "behave as usual" were indicated twice as barriers for applying HDP training skills in classroom teaching.

\subsection{Interview responses from department heads}

Application of Higher Diploma training skills.

Department heads were asked to explain how far HDP graduates from their respective department were using student centred approach in their classroom teaching. Accordingly, their interview responses schemed as: applying as planned, there is a change but not to the expected level, and no change at all. This is provided in Table 9.

Table 9. Application of active learning by graduates of HDP as reported by department heads.

Application of a student centred approach

$\mathrm{n}=10$

Applied as planned

1 (A/Oromo)

Change in approach but not as expected

6(Geography, Amharic, Maths, History, Biology \& English)

No change in the previous approach

3 (Pedagogy, Chemistry, Physics) 
As represented by Table 9, majority of heads (5) believed that even though there were change in knowledge, attitude and skill regarding a student-centred approach as a result of HDP training, instructors were not using the skill in the classroom teaching to the required level. The other three heads of departments stated that their staff did not bring change in the way they were teaching after having graduated from HDP. Only one head reported that his staffs graduating from HDP was applying a student-centred approach as wanted. $\mathrm{He}$ further elaborated that people who have graduated from HDP were left for further education except one. The others were new employee; hence, they are attending the HDP by then. As to the person graduated from the HDP, he mentioned, he is confident on him that he is using the skill effectively since he is educator of HDP. Evidence from classroom observation and interview with the corresponding instructor confirmed the same thing.

Department heads whose response categorized as there is a change but not as expected and no change in approach have asked for further explanation. And they provided the following justification:

Table 10. Justifications for not applying a student-centred approached to the required level as reported by department heads.

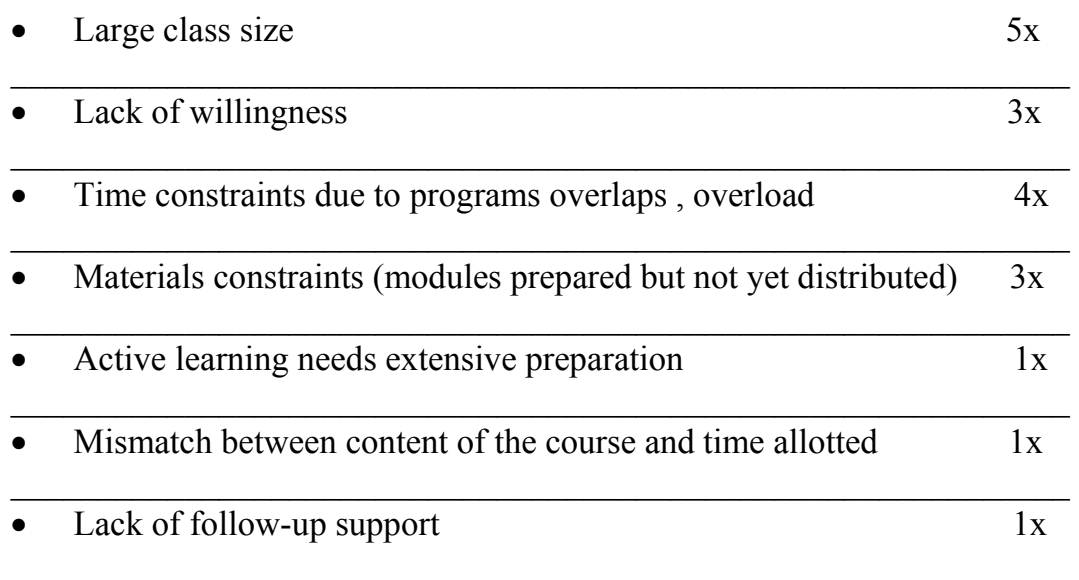

Accordingly, major bottlenecks for application of HDP training skills (a student-centred approach) into classroom practice were large class size $(4 x)$, time constraint due to over load or program overlap (4x), and lack of willingness (3x). Material constraints, the need for extensive preparation, mismatch between content of the course and time allotted as well as lack of follow-up support were also indicated as barriers. The following quotes referring to the aforementioned barriers were taken from the interview with department heads.
Large class size

"...there is a change in methodology we are using before taking HDP and now. However, I do not mean that we are applying the skill exactly in the way we learn to be, as the existing problem [class size] continue to aggravate. At the beginning of this year 198 fresh students were assigned to the department and we were forced to assign them only in to two sections. $\quad .$. finally the class was overcrowded, no chair for students, no space to put chair and every things went 
wrong. After one month trial, we continued debating with university officials and finally managed to make three sections, 65 students per section. Still, 65 is large and we could not proceed with active learning as expected. We have the knowledge, the skill but these all messes lead us to leave the practice even at all."

Time constraint due to overload or program overlap

"There is a program called CBTP which is amalgamation of Practicum and CBE. During this program, instructors are assigned as supervisor and go for outreach. In our department, one instructor is teaching at least two batches. When they go for supervision with one batch, class for other batch will stop. ...a student centred approach is time taking. It needs you to have patience until students perform individually, exchange idea and come to conclusion by themselves. However, this instructor left his classes for practicum purpose let say for one month. When he came back from practicum, examination period can be approached. Therefore, to cope with this the person forced to cover the portion by calling make up, then by telling [lecture method] than employing active learning.

\section{Unwillingness of instructors}

"There are people who are certified with HDP. However, they have not yet shown any change in their teaching. From the beginning, our staffs were not interested in the program. As a result, some of them quitted in between like me, while others graduated with low performance. We did not believe in the usefulness of the program. We were recommended and forced to take the training without involving us in the decision".
With regard to the existence of provision of work place support or follow-up service for graduates of HDP, all department heads reported that their academic staffs have received no support although there was a plan called Continuous Professional Development $[\mathrm{CPD}]$ that planned for the aforementioned purpose. However, they reported that CPD has not yet implemented for unknown reason. Although participants of this study perceived CPD as a program designed to provide follow-up support for HDPT, the objective of CPD is more general than that. It is designed to up-dated teachers to new policies, reforms introduced that help teachers to renew their teaching license any time new reforms introduced (TGE, 1994; TESO, 2003; MOE; 2006).

\subsection{Summary of interview responses with dean}

In response to question addressing the implementation of a student-centred approach by HDP graduates, the dean responded that at the faculty level he could not say exactly they are implementing or not as far as no consistent follow up has taken place. However, since he himself is a graduate of HDP, he concluded from his experience that HDP training skill is rarely applied. He attributed the failure to the following points.

- Large class size. He witnessed that he has around 85 students in one class.

- Lack of readiness from the student side. The dean reported that students were not welcoming a student-centred approach. Unless the instructor used lecture method, students did not consider that they were learning. Comparing to students from other faulty, he described the Education Faculty students as showing low attempts to learn themselves. He said, therefore, at the end of the day when his students could not learn what they supposed to learn, he would back 
to the traditional method. Therefore, he said that he was rarely applying the method.

The dean was asked if there was any follow-up support arranged for HDP graduates that could enable them to implement a student centred approach. Accordingly, he gave the following responses.

There was a program called continuous professional development designed in order to check whether the graduates are applying the skill or not. The program was thought to be conducted by leaders involved in HDPT. However, he said that he was not sure that leaders did it. This might be due to time constraint as these leaders are giving courses besides leading HDP. Although the faculty reduces their teaching load, still they are overloaded with additional programs like practicum and CBTP. Besides, he mentioned that he was in doubt that the leaders were thought in depth and planned for continuous professional development.

Above all, he said no follow-up plan was designed. He mentioned that even he was worried for the sustainability of HDP than for the follow-up since HDP is currently supported from Teacher Development Fund [TDP] where more than 5,000 birr has been paid for single leader per semester. For this semester, the faculty paid more than 40,000 birr for 8 leaders. Therefore, if TDP fund terminated he expressed his doubt that the University could afford this much money. Another factor for the absence of follow up service, as described by the dean, is attributed to lack of one responsible organizer. Nowadays, instructors are running the program side to their normal class. No person is assigned or employed only for such purpose. Even some people after they trained and experienced well for the leading, they are joining another position.

Therefore, the dean stressed that in order to confirm the sustainability of the program, instructors must believe in the value of a student-centered approach in bringing radical improvement in the performance of students. This can be done through using of practical changes in the form of case studies; showing video evidences of one full class where a student-centered approach is all implemented and discussing about it than blindly forcing instructors. These techniques could accelerate understanding of the program's value by teachers. If so, instructors can force themselves to apply a student-centered approach without any reinforcement or enforcement. In addition, making related conditions conducive (such as classroom environment, minimizing over load, assigning one responsible person freed from teaching) can facilitate application of a student-centered approach.

\section{DISCUSSION}

As shown in Section 3, instructors with high teaching experiences and second degree holders were participated in the study since during training of HDP; priority has given to people who hold position and with high experiences. As a result, majority of the young staffs have taken the training thereafter. Besides, those people who have Bachelor degree and have graduated from HDP have been already sent for further education. All of the participants have gone through Teacher education systems. The average teaching load for instructors in the faculty of Education in general was 11 hours per week excluding other related activities such as advising and supervising CBTP though maximum load set is 12 credit hours per week. Therefore, the teaching load of participants was not 
exceeding the maximum load. Similarly, the average number of courses taught by instructors was 2 (see table $2 \& 3$ ).

\section{Application of HDP training skills by HDP graduates}

Accordingly, evidences from lesson observation showed that only three instructors (I4, I8 \& I9) were observed going smoothly through all parts of the lesson using a student-centred approach. The rest (except I2 \& I3) were begun making the lesson participatory in the introduction part but soon fall back to the traditional lecture method. Commonly, maximum of five minutes is expected to be devoted on each of introduction and conclusion part of the lesson. One period corresponds to fifty minutes. Therefore, much time is allocated to the body of the lesson. However, as indicated in the above paragraph only three instructors managed to make their instruction a student centred while carrying out the body of the lesson. This implied that other instructors covered the whole periods using lecture method. In support to this finding, Daniel (2004) express lecture method as dominating instructional approach that used in higher learning institutions of Ethiopia. He goes on pointing to the drawbacks of this method as students tend to depend primarily on lecture notes that highly discourage independent learning.

Nevertheless, some of them tried to support their lecture with questioning although still the questions were strictly close ended like asking for meaning, a word and so on. Besides, majority of them did not give time for students to think and respond. Rather they forwarded the question then responded themselves without involving students. Specially, three instructors were continuously using questions but they called on students who were not raising hands. In their view, calling on students who are not raising hands can increase the participation of all students or at least help to get their attention as they are expecting questions. However, their requirement for students who are not ready to give answer could not contribute to an atmosphere that encourages students' involvement in discussion. This finding is consistent with previous finding in the case of Ethiopian HEIs (Tolessa, 2004).

Of course, the success of the abovementioned three instructors can be attributed to different factors. Among the observed participants, they were observed teaching final year students (except I8 but who was also observed teaching small class size) who are small in size, unlike the first and second year students. Second, I8 \& 9 were teaching national and regional languages, respectively that are mother tongue for both students and instructors. Emerging literatures from South Africa context showed that medium of instruction (English) became barrier in applying a student centred approach of instruction in secondary education as far as the language is not mother tongue for both teachers and students (Thijs, 1999; Ottevanger, 2001). Therefore, this might be the case in the aforementioned point although detailed research has not yet conducted concerning Ethiopia. This can be potential area for further research. Lastly, I9, who succeeded in making his lesson student centred, is currently educator of HDP. This also might initiate the person to use the skill.

It is also these two language instructors observed using different active learning methods; maintaining teacher-student talk balance as well as encouraging participation of female students. They were the only instructors used continuous assessment during classroom observation. None of instructors were observed using 
lesson plan so it is difficult to comment on their time management skill.

Evidences derived from interview with the observed instructors, corresponding department heads and faculty dean even revealed less regarding the use of HDP training skills. Only two instructors (the two language instructors) considered their then approach as a student-centred. Even among them one was said during interview (see section 3 ) he made his teaching learner centered just on the observation day due to the nature of the then lesson. Moreover, among department heads, only one reported that HDP graduates from his department (the one claimed him self using student centred approach always) currently using student centred approach effectively. Dean of the faculty also reflected his doubt about how far instructors are using this approach.

Moreover, analysis of classroom observation and interview with instructors showed that instructors were using traditional learning methods such as questioning, gapped lecture, and individual work (TESO, 2003). The nature of these methods and also the way they used were not encouraging the participation of students. Use of close ended questions and forcing student to reply or participate shouldered the aforementioned risk. Moreover, the abovementioned methods are not encouraging as they prevent students learn from each other.

Factors inhibiting the successful application of HDP Training skills at a Classroom level

Large class size: In order to conduct a student-centred approach, the number of students in a given class should be reasonable so that instructors able to identify each student by name; give feedback to the performance of students on time and all students got chance to express their view. Moreover, at least the number of student and the size of the classroom should fit each other so that at least instructor gets passage to go within the group and guide or monitor students' activities. At the same time, students should also get enough space to move freely while forming group for discussion and backing to their seat without disturbing neighboring classes. However, from the researcher's experience during classroom observation and as reported by instructors, department heads and deans during interview, these all conditions were not observed in the context of education faculty. Except for final year classes and one class from other batch, all batches have minimum of 65 students in a class. Even sometimes latecomers forced to find chairs from neighboring classes. In this way, the place for teacher to step on is limited to the front corridor. The researcher witnessed this condition from his experience of classroom observation with at least four departments. In opposite to this view, one instructor, the one observed approximately teaching 80 students in a class, argued that he did not belief in idea that large class size prevents instructors from applying active learning methods. He stressed that if other conditions fulfilled besides the presence of determination from the instructor side, the effect of class size might not be significant.

The need to cover the portion: the participants agreed that the contents of the course and time allotted for do not much each other. However, it is known that using of a student-centred approach compared to traditional lecture method is time taking. That is why instructors mentioned their worries that they could not complete the lesson if they used a student-centred approach. In line with this idea, several literatures advocating constructivism argue that students should be encouraged to learn 
explore their ideas (preferably in collaboration) and develop deep knowledge, and skill (Kwakman, 2003; Jonassen, 1999). To ward this end, students need to be provided with less content with ample time (Jonassen, 1991; TESO, 2003; Trends in International Mathematics and Science Study [TIMSS], 2003). As I shall argue later in this paper, it would have been possible to make instruction a student centred approach despite the vastness of the lesson, if students have had learning materials (such as books, modules etc) at hand. Had it been so it would have been possible for instructors to cover the portion through provision of home work, reading assignments, group work, and so on, which are also methods of active learning.

Lack of learning materials at hand: both instructors and department heads have stressed problems related to lack of materials at hand for students. They have mentioned that modules were already prepared but not yet distributed for students. One instructor emphasized this condition as follow:

“... in our case, conditions are not favorable to make instruction a student centred. Students have no learning materials at their hand. Had it been so or had it been I would have facilities that would helped me to produce and distributed materials, it would be very easy to make the lesson attractive. Despite this all challenges, sometimes I tried to produce and distributed materials to students. But the problem is that if you go to office now and then and ask secretaries for photocopies, printer, or duplication, they get bored and start nagging at you. They start responding that they do not have paper, ink and so on."

Therefore, if we want students learn themselves leaving aside the passive, traditional and one way approach of instruction, we should provide them with the appropriate learning resources with which they will interact. If so, the task of teachers will be limited to facilitator while those students will be doer and learner at every time and place. Thus, the teacher won't be worried to cover the portion for students can do lots of things themselves outside of the class time.

Lack of interest from students and teachers side: Other factor mentioned as a barrier for application of HDP training skills approach were lack of interest from student and instructors side in using student-centered approach. Instructors, heads and dean agreed that students were not considering that they learned when instructors used active learning methods in delivering the lesson. This might be due to the fact that a student centered approach requires effort from students in contrary to the traditional lecture methods, which required them merely to memorize the ready-made note and answer examination. Besides, in Ethiopia, most students forced to join Education faculty. These are among students who have low score on National examination. As a result, less prepared students are joining the faculty. Thus, it would be difficult for them to lean by themselves. Consequently, they are considering that they are not learning while instructors using a student-centred approach. Regarding instructors, most of them have trained under the traditional lecture method so they might resist for a change as Jonassen (1991) said old habit die hard.

"The need to behave as usual": The objective of the researcher was to observe the natural environment of classroom practice. To do this, an attempt was made to request willingness of an instructor and observe him/her on the same day. 
However, the researcher was not successful in doing so for some respondents due to different factors. As a result some instructors asked him the way he wanted them to be in order to organize themselves in that way. As a result, he requested them to behave as they did before. Finally, two interviewees reported that they could make the then lesson a student centred but they did not since they were already informed to act as they did teach before. This showed that (as argued later) if there was something that enforces or reinforces instructors to use a student-centred (HDP training skills) they would have used it. This can be consolidated from this writer's experiences that most instructors adjust themselves to such limitations during peer observation or observation by HDP's managing group. This shows that the presence of others pressurized the instructors to apply the training skill in their classroom instruction. In line with this idea, Fullan (2001) indicates the need for accompanying pressure with support in directing teachers toward using of innovation. Because, he argues, teachers need pressure even in the direction they want.

Lack of well organized workplace follow-up support: all participants confirmed that workplace follow-up support that can enforce or reinforce the graduates to use the training skills has not yet designed both at the department and faculty level. This can be attributed as major cause for the failure of the application of the training skills.

\section{Conclusions and recommendations}

In general, HDP graduates are not applying a student-centred approach in their classroom teaching to the desired level. They couldn't make their lesson studentcentred at the different phase of the instruction (introduction, body of the lesson and conclusion) except those who were observed teaching national and regional languages. Majority of the instructors observed supporting their lecture with questioning. However, the way they used were not encouraging the participation of students. Moreover, the graduates were applying rarely continuous assessment though it was difficult to decide their skill of time management for no observed graduates were using lesson plan.

Factors for the failure of implementing HDP training skills at a classroom level attributed not only to the physical constraints such as large class size, lack of learning materials at hand, and mismatch between course content and time allotted but also to the absence of interest from instructors and students side and absence of well organized follow-up support that enforces or reinforces instructors to use the training skills.

As the country's economy level does not allow constructing many classrooms and employing ample human resource within a short time, awaiting the resolution of such physical constraints again could take us a century to complete the reformation envisaged. It is also impractical to raise the habit and level of students at once so that application of students' centred instruction is possible. The impracticality for having the required instructors both in quality and in quantity is another factor. It is also worthwhile to think that teacher educators cannot be equipped with skill of learnercentred instruction within one year training. Having this in mind, the study recommends the following strategies as a remedy for the prevailing problem:

- Additional training should be provided for instructors on how to involve learners at different stage of lessen presentation, appropriate 
use of question, and strategies to implement active learning and continuous assessment in large class.

- Further studies should be undertaken so as to identify if medium of instruction is a barrier for implementing a studentcentred learning in the context of Ethiopia.

- Strategies by which the learning materials (the developed materials) available for students should be provided soon. It can be done in such away that enough copies will be duplicated and students should borrow it.

- HDP office should give equal emphasis to the follow-up service like that of initial training. There should be on workplace support that pressurized instructors to use the training skills.

- Awareness raising activities should be provided for students on the benefit of learning by doing than learned through cooked book approach.

\section{REFERENCES}

Daniel, T. (2004). Reflection on quality of research in Ethiopia higher education institutions. The Ethiopian Journal of Higher Education, 1(1), 41-55.

Federal Democratic Republic of Ethiopia (FDRE) (2004, September). Report of federal

government on development of education in Ethiopia to UNESCO forty seven

session of the international conference on education. 8-11 September, 2004, Geneva, Switzerland.
Fullan, M. (1991). The new meaning of educational change (second ed.). New York: Teacher College Press.

Fullan, M. (2001). The new meaning of educational change (Third Ed.). New York: Teacher College Press.

Guskey, Th.R. (2000). Evaluating professional development. Thousand

Oaks, California: Crown press.

Higher Education Systems Overhaul (2004). Report of the higher education strategy overhaul committee of inquiry into governance, leadership and management in Ethiopia's higher education system. Addis Ababa, Ethiopia: Ministry of Education.

Jonassen, D. H. (1991). Objectivism versus constructivism: Do we need a new philosophical paradigm? Educational Technology Research and Development, 39(3), 5-14.

Jonassen, D. H. (1999). Designing constructivist learning environments. In C. M. Reigeluth (Ed.), Instructionaldesign theories and models: volume 2-A new paradigm of instructional theory (pp. 215-239). Mahwah, NJ: Erlbaum.

Kwakman, K. (2003). Factors affecting teachers' participation in professional development

earning activities. Teaching and Teacher Education, 19 (5), 149-170

Ministry of Education [MOE] (2006). Guidelines prepared to lead, follow-up, and valuate activities of teacher development program. $4^{\text {th }}$ abstract. Unpublished manuscript.

Ottevanger, W ( 2001). Teacher support materials as a catalyst for Science Curriculum implementation in Namibia. Doctoral Dissertation, Enschede:University of Twente 
Silverman, D. (1993). Interpreting Transitional Government of Ethiopia qualitative data: Methods for analyzing (TGE). (1994). Education and training talk, text and interaction. London: Sage. $\quad$ policy. Addis Ababa, Ethiopia: Author.

Teacher Education System Overhaul [TESO] (2003). Handbook. Addis Ababa, Ethiopia: Ministry of Education.

Thijs, A.M. (1999). Supporting science curriculum reform in Botswana: The potential of peer coaching. Doctoral Dissertation, Enschede: University of Twente.

Tolessa, T. (2004). Teaching methods in agricultural colleges and universities in Ethiopia: The case of Ambo Agricultural College, IER FLAMBEAU ,11 (2), 15-20.

Trends in International Mathematics and Science Study (2003). TIMSS assessment frameworks and specifications 2003. $2^{\text {nd }}$ Ed. US, Boston College: IEA

Wragg, T.(2002). Interviewing. In Coleman, M., \& Briggs, A. R. (Eds.), Research Methods in Educational Leadership and Management (pp. 143158). London: Paul Chapman Publishing.

Yin, R.K. (1994). Case study research: Design and methods. Beverly Hills, CA: Sage

Publications. 